\title{
Sistem Informasi Reservasi Lapangan Futsal Berbasis Web dan Whatsapp Gateway Pada Bee Futsal
}

\author{
Kurniasari ${ }^{1}$, Abrar Hiswara ${ }^{1}$, Rafika Sari ${ }^{1, *}$ \\ * Korespondensi: rafika.sari@dsn.ubharajaya.ac.id
}

\author{
1 Informatika; Fakultas IImu Komputer; Universitas \\ Bhayangkara Jakarta Raya; Jl. Raya Perjuangan, \\ Margamulya, Bekasi; telp.(021) 7231948; \\ kurniasari16@mhs.ubharajaya.ac.id, \\ abrar.hiswara@dsn.ubharajaya.ac.id, \\ rafika.sari@dsn.ubharajava.ac.id.
}

Submitted: $\mathbf{1 0}$ Maret 2021

Revised: 31 Maret 2021

Accepted: 21 April 2021

Published: 25 Mei 2021

\section{Abstract}

This study discusses the making of a field reservation information system with the aim of making it easier for customers to make field reservations at Bee Futsal, making it easier for Bee Futsal staff in managing field reservation data, and minimizing the risk of data loss, and can simplify information about the time delay limit according to the schedule. determined. This information system development uses the programming language PHP, HTML, and Java Script and uses the MySQL database. This information system developmentmethod uses the waterfall method. The results of this study can be implemented in the form of a web-based field reservation information system and whatsappgateway.

Keywords: Field Reservation, Information System, Web Based, Waterfall, Whatsapp Gateway

\section{Abstrak}

Penelitian ini membahas tentang pembuatan sistem informasi reservasi lapangan dengan tujuan untuk mempermudah customer dalam melakukan reservasi lapangan pada Bee Futsal, mempermudah staff Bee Futsal dalam pengelolaan data reservasi lapangan, d a n meminimalisir resiko kehilangan data, Sisa mempermudah in formasi mengenai batas keterlambatan waktu sesuai jadwal yang telah ditentukan. Pengembangan sistem informasi ini menggunakan bahasa pemrograman PHP, HTML, dan Java Script serta menggunakan database MySQL. Metode pengembangan sistem informasi ini menggunakan metode waterfall. Hasil dari penelitian ini dapat diimplementasikan dalam bentuk sistem informasi reservasi lapangan berbasis web dan whatsapp gateway.

Kata kunci: Sistem Informasi, Berbasis Web, Reservasi Lapangan, Waterfall, Whatsapp Gateway. 


\section{Pendahuluan}

Perkembangan teknologi informasi yang berkembang pesat sekarang ini telah mendorong pertumbuhan diberbagai bidang informasi. Secara langsung atau tidak, teknologi informasi telah menjadi bagian penting kebutuhan karena banyak kemudahan yang ditawarkan. Teknologi informasi hampir tidak dapat dilepaskan dari berbagai aspek kesehatan, pendidikan, sampai olahraga.

Olahraga indoor saat ini menjadi salah satu yang banyak diminati oleh berbagai kalangan. Salah satu olahraga indooryang banyak digemari salah satunya ad al ah olahraga futsal. Olahraga futsal merupakan olahraga sepakbola mini yang dilakukan dalam ruangan dengan panjang lapangan 38-42 meter dan lebar 15-25 meter. Diamainkan oleh 5 pemain termasuk penjaga gawang. Futsal adalah permainan yang hamper sama dengan sepakbola, dimana dua tim memainkan dan memperebutkan bola diantara para pemain dengan tujuan dapat memasukkan bola kegawang lawan dan mempertahankan gawang dari kemasukan bola (Ameldi \& Ahsyar, 2018).

Bee Futsal adalah salah satu penyedia bisnis penyewaan lapangan futsal di daerah Cengkareng, Jakarta Barat. Bee futsal memiliki 3 lapangan semi indoor beralas rumput sintetis dengan ukuran standar dan internasional, dengan kualitas lapangan yang sangat baik. Selain itu fasilitas penunjang kegiatan futsal di Bee Futsal juga sangat lengkap. Hal ini yang menyebabkan Bee Futsal menjadi penyedia penyewaan lapangan futsal yang cukup terkenal dikalangan warga Cengkareng.

Reservasi adalah sebuah proses perjanjian berupa pemesanan sebuah produk baik barang maupun jasa dimana pada saat itu telah terdapat kesepahaman antar konsumen dengan produsen mengenai produk tersebut namun belum ditutup oleh sebuah transaksi jualbeli. Pada saat reservasi berlangsung biasanya ditandai dengan adanya proses tukar menukar informasi antara konsumen dan produsen agar kesepahaman mengenai produk dapat terwujud (Ameldi \& Ahsyar, 2018). Dengan banyaknya jumlah reservasi setiap bulannya diperlukan suatu sistem untuk mengontrol proses reservasi lapangan futsal agar data reservasi d apat dikelola dengan baik. Sistem didefinisikan sebagai sekumpulan prosedur yang saling berkaitan dan saling berhubung untuk melakukan suatu tugas bersama-sama (Pratama, 2014). Sistem adalah kumpulan atau himpunan dari unsur atau variabel-variabel yang saling terkait, saling berinteraksi, dan saling tergantung satu sama lain untuk mencapai tujuan (Tohari, 2014).

Selain itu customer kadang sering kesulitan saat ingin memesan lapangan dikarenakan sistem pemesanan masih menggunakan cara manual yaitu dengan cara mendatangi tempat Bee Futsal telebih dahulu untuk menanyakan ketersediaan lapangan. Untuk mengatasi permasalahan itu, maka perlu dibangun suatu sistem yang terkomputerisasi. Sistem tersebut dapat digunakan sebagai alat bantu terutama untuk proses pengelolaan data dan mempermudah customer dalam melakukan reservasi lapangan.

Sistem informasi berbasis website adalah salah satu sistem informasi yang sangat diminati di Indonesia. Selain memiliki jangkauan pemasaran yang luas website juga sangat 
mudah untuk diakses. Hanya dengan terhubung ke internet siapa saja dapat mengakses sebuah website. Menurut Asosiasi Penyelenggara Jasa Internet Indonesia (APJII) jumlah pengguna internet hingga kuartal II tahun 2020 sebanyak 196.7 juta jiwa. Hal ini tentunya dapat dijadikan landasan sistem yang akan dibuat agar kedepannya sistem ini juga dapat berfungsi sebagai ajang promosi Bee Futsal.

\section{Metode Penelitian}

Beberapa metode penelitian yang digunakan peneliti dalam penelitian ini menggunakan yaitu:

\subsection{Metode Pengumpulan Data}

Metode pengumpulan data yaitu cara memperoleh sekumpulan data yang diperlukan dalam penelitian ini yaitu dengan cara (a) Observasi, pengumpulan data dengan mengadakan peninjauan serta pengamatan secara langsung guna memperoleh data di Bee Futsal; (b) Wawancara, pengumpulan data melalui tanya jawab langsung dengan admin yang berhubungan langsung dengan prosedur tersebut. Wawancara ini dilakukan langsung dengan tatap muka (face to face interview); (c) Kuesioner, peneliti melakukan pengumpulan data dengan mengajukan beberapa pertanyaan dan menyebarluaskan pertanyaan tersebut untuk dijawab melalui Google form kepada responden; (d) Studi Kepustakaan, untuk melengkapi informasi yang diperlukan dalam penelitian skripsi ini, peneliti juga melakukan penelaahan terhadap buku-buku atau referensi, literatur-literatur, catatan-catatan, dan internet serta laporan-laporan yang berhubungan dengan penelitian ini, agar diperoleh data-data yang mendukung.

\subsection{Metode Pengembangan Sistem}

Metode waterfall merupakan metode yang sering digunakan oleh penganalisa sistem pada umumnya. Inti dari metode waterfall adalah pengerjaan dari suatu sistem dilakukan secara berurutan atau secara linear. Jadi jika langkah ke-1 belum dikerjakan, maka langkah 2 tidak dapat dikerjakan. Jika langkah ke-2 belum dikerjakan maka langkah ke-3 juga tidak dapat dikerjakan, begitu seterusnya. Secara otomatis langkah ke-3 akan bisa dilakukan jika Iang kah ke-1 dan ke-2 sudah dilakukan (Septavia et al., 2016).

Dalam penelitian ini digunakan pula bahasa pemrograman PHP, yaitu bahasa script server side yang dapat digunakan dengan bahasa HTML atau d okumen secara bersamaan untuk membangun sebuah aplikasi web. Sifat open source pada PHP memberikan kemampuan PHP berkembang secara cepat (Kurniawan, 2020). Selanjutnya digunakan pula PhpMyAdmin, sebuah aplikasi/perangkat lunak bebas (open source) yang ditulis dalam bahasa pemrograman PHP yang digunakan untuk menangani administrasi database MySQL melalui jaringan lokal maupun internet. PhpMyAdmin mendukung berbagai operasi MySQL, diantaranya (mengelola basis data, tabel-tabel, bidang (fields), relasi (relations), indeks, pengguna (users), perijinan (permissions), dan lain-lain (Erma Standsyah \& Sari Restu, 2017). Pola yang diambil untuk mengembangkan sistem perangkat lunak pada penelitian ini adalah SDLC (System 
Development Life Cycle) yang terdiri dari lima kegiatan utama, yaitu: analisis, desain, implementasi, pengujian, dan pemeliharaan (Widharma, 2017). Untuk software database di gunakan MySql, yaitu salah satu Relational Database Management System (RDMS) bersif at open source. Struktur database disimpan dalam tabel-tabel yang saling berelasi. Karena bersif at open source, MySql dipergunakan dan didistribusikan baik untuk kepentingan individu maupun corporate secara gratis, tanpa memerlukan lisensi dari pembuatnya. MySql dapat dijalankan dalam berbagai platform sistem operasi antara lain Windows, Linux, Mac OS, Sun OS dan lain-lain (Masrur, 2016).

Pada penelitian ini, usecase diagram sistem informasi penyewaan lapangan Bee Futsal terdiri dari 2 aktor dan 10 usecase. Gambar 1 merupakan usecase diagram sistem informasi penyewaan lapangan Bee Futsal. Use Case digunakan untuk mengetahui fungsi apa saja yang ada di dalam sebuah sistem informasi dan siapa saja yang berhak menggunakan fungsi-fungsi itu." (Sukamto, 2013).

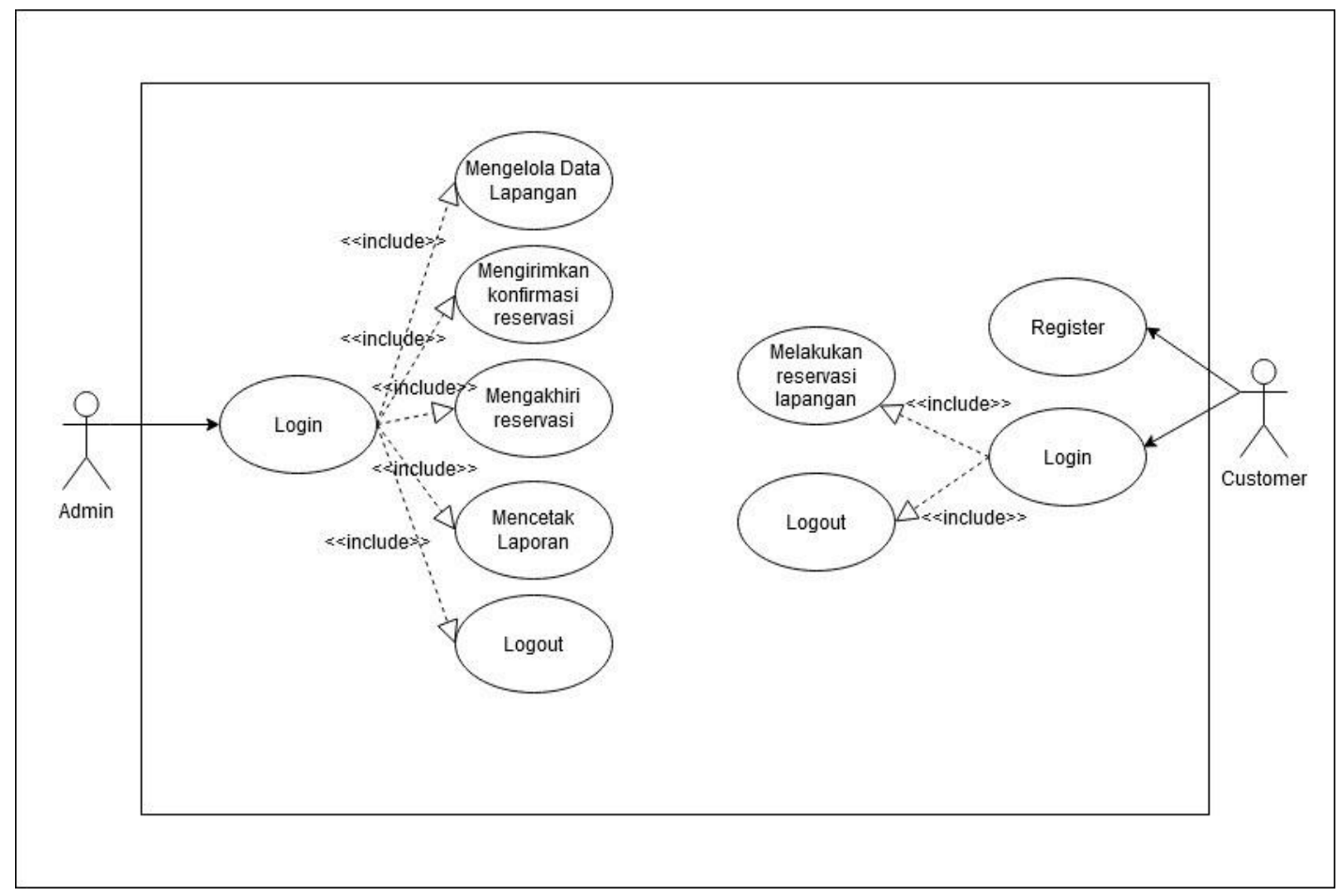

Sumber : Hasil Penelitian (2020)

Gambar 1. Usecase diagram sistem informasi penyewaan lapangan Bee Futsal

\subsection{Metode Pengujian}

Pada tahap pengujian, peneliti menggunakan metode Black Box Testing. Menurut (Jaya, 2018) Black Box Testing merupakan teknik pengujian perangkat lunak yang berfokus pada spesifikasi fungsional dari perangkat lunak. Black Box Testing bekerja dengan mengabaikan struktur control sehingga perhatiannya difokuskan pada informasi domain. Black Box Testing memungkinkan pengembang software untuk membuat himpunan kondisi input yang akan melatih seluruh syarat-syarat fungsional suatu program. 


\section{Hasil Dan Pembahasan}

Berikut adalah hasil penelitian berupa screenshoot dari aplikasi Web dan Whatsapp Gateway yang digunakan dalam perancangan sistem informasi reservasi lapangan futsal $p a d a$ Bee Futsal.

a. Tampilan Halaman Login Admin

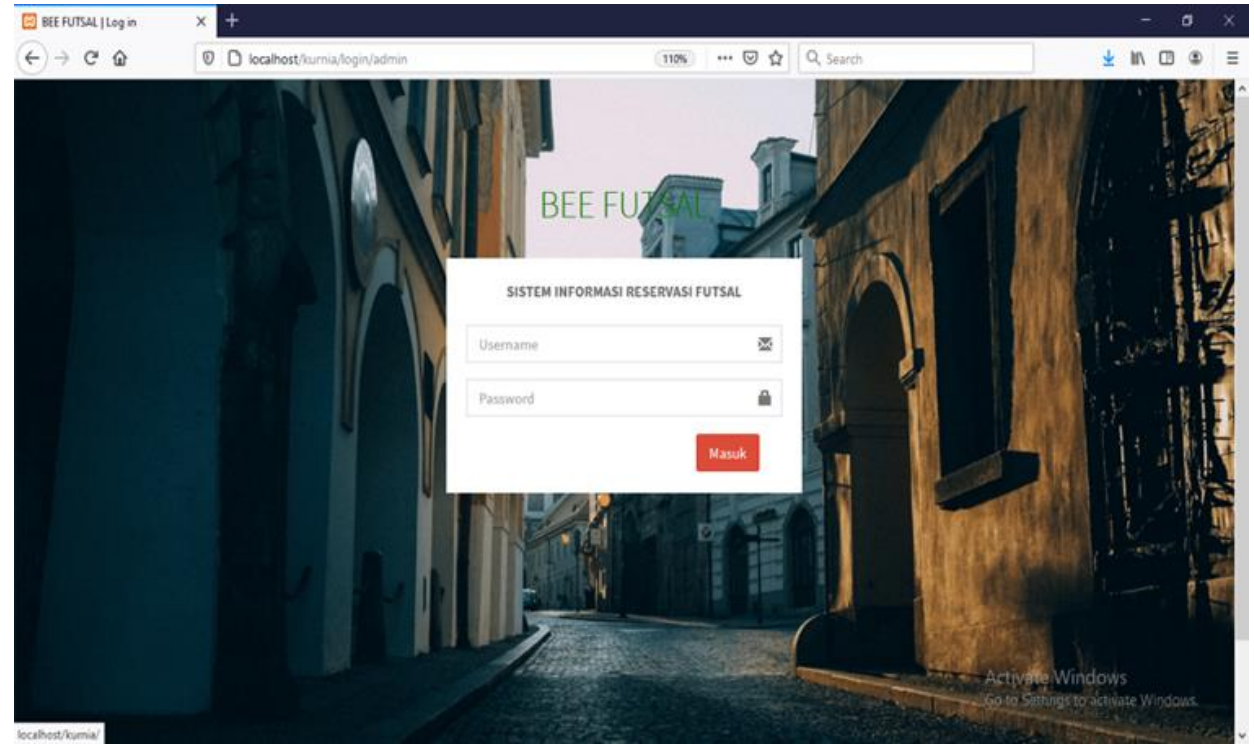

Sumber : Hasil Penelitian (2020)

\section{Gambar 2. Login Admin}

Gambar 2 merupakan tampilan dari halaman login admin pada sistem reservasi lapangan futsal yang saya buat. Pada halaman ini admin dapat melakukan login dengan cara menginput username dan password yang telah didaftarkan.

b. Tampilan Halaman Menu Data Lapangan

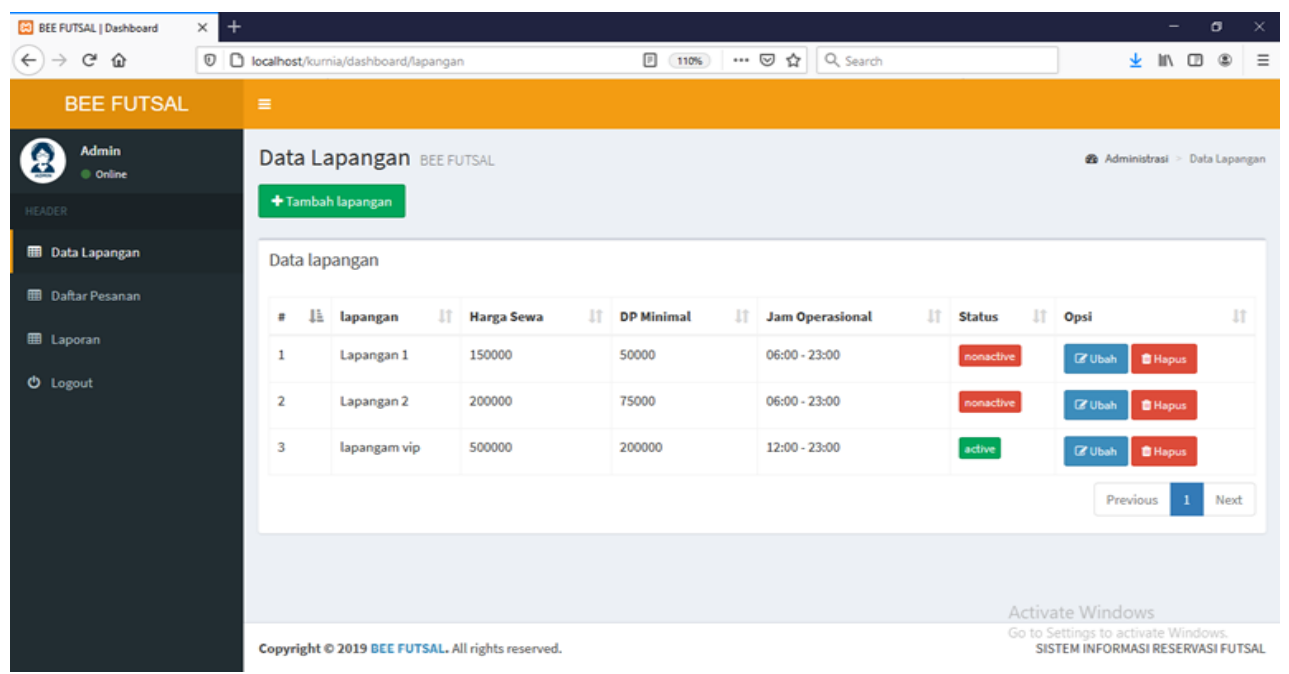

Sumber : Hasil Penelitian (2020)

\section{Gambar 3. Menu Data Lapangan}

Gambar 3 merupakan tampilan dari menu data lapangan yang hanya bisa diakses oleh seorang admin setelah melakukan login. Pada menu data lapangan ini seorang ad min dapat 
mengontrol keseluruhan lapangan dengan cara menambahkan lapangan baru, menghapus lapangan yang sudah ada dan mengubah deskripsi lapangan yang ada.

c. Tampilan Halaman Menu Daftar Pesanan

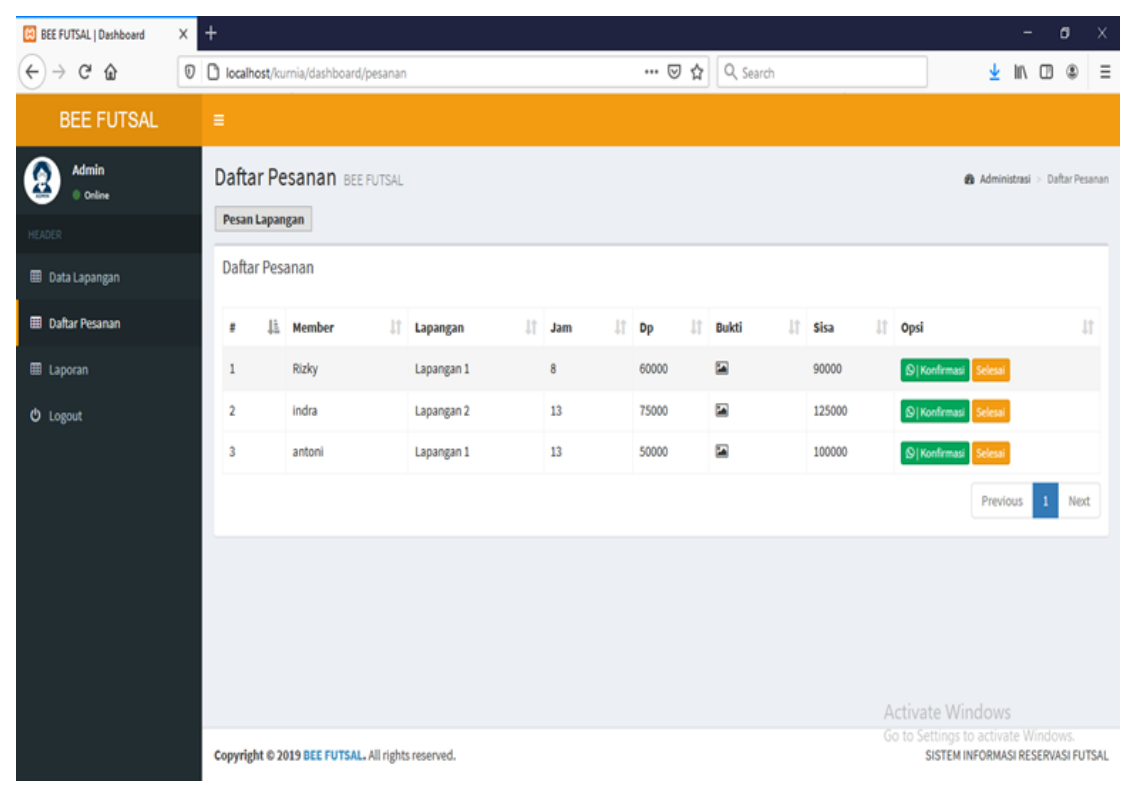

Sumber : Hasil Penelitian (2020)

\section{Gambar 4. Menu Data Pesanan}

Gambar 4 merupakan tampilan dari menu daftar lapangan yang akan dipesan. Pada menu daftar pesanan ini seorang admin dapat mengetahui lapangan mana saja yang telah direservasi. Dan untuk selanjutnya akan melakukan tahap konfirmasi dan remainder kepada para customeryang melakukan reservasi.

d. Tampilan Halaman Menu Laporan

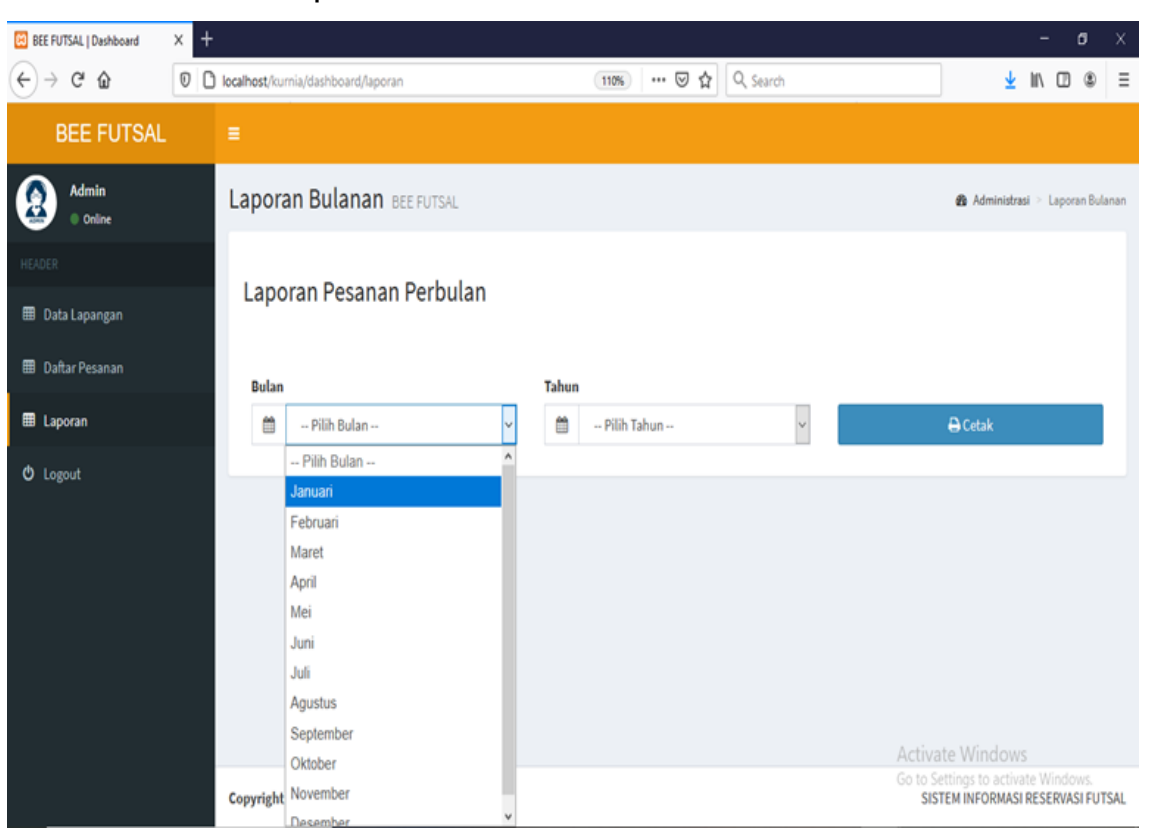

Sumber : Hasil Penelitian (2020)

Gambar 5. Menu Laporan 
Gambar 5 merupakan tampilan dari menu laporan yang hanya bisa diakses oleh sorang admin setelah melakukan login. Pada menu laporan ini kita bisa membuat Iaporan reservasi dalam satu bulan dengan cara memilih bulan dan tahun dari laporan reservasi yang di inginkan.

e. Tampilan Halaman Menu Customer

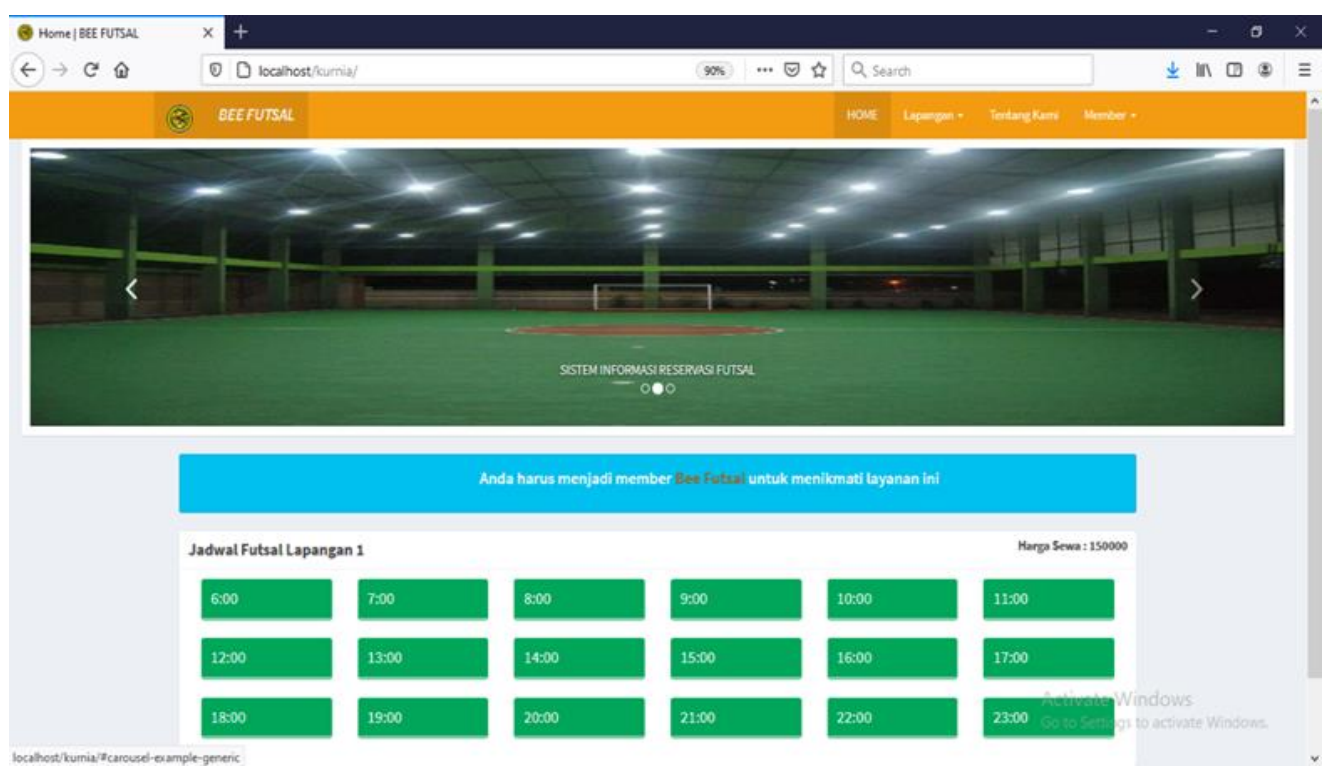

Sumber: Hasil Penelitian (2020)

Gambar 6. Menu Customer

Gambar 6 merupakan tampilan halaman menu customer. Di halaman ini pihak customer yang akan melakukan reservasi lapangan dapat memilih sebuah lapangan pada daftar lapangan yang tersedia dan menentukan pukul brapa lapangan itu akan dipesan.

f. Tampilan Form Register

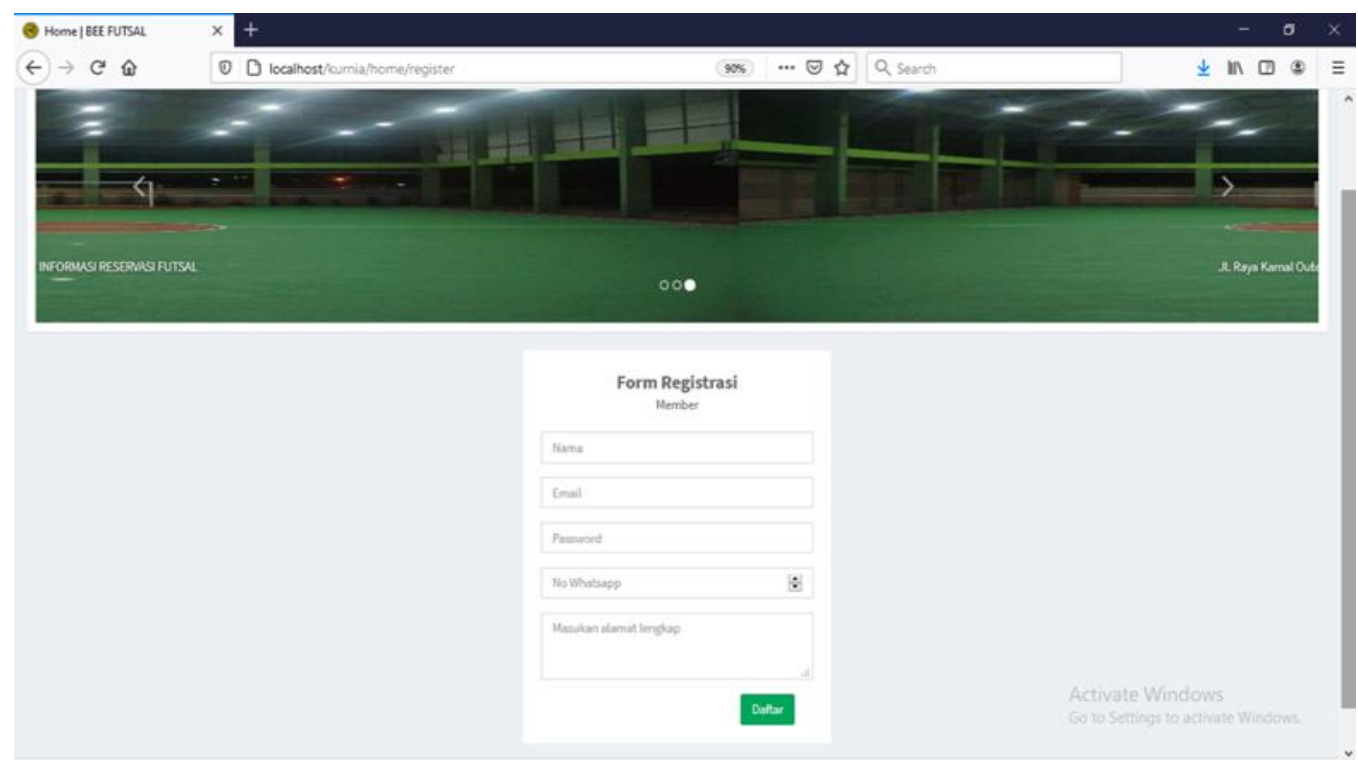

Sumber : Hasil Penelitian (2020)

Gambar 7. Form Register Member

Gambar 7 merupakan tampilan halaman dari form registrasi member customer. Jadi sebelum memesan lapangan pihak customer harus melakukan registrasi akun terlebih dahulu, 
agar pihak dari bee futsal dapat memperoleh informasi tentang customer yang mereka butuhkan.

g. Tampilan Halaman Form Login Member

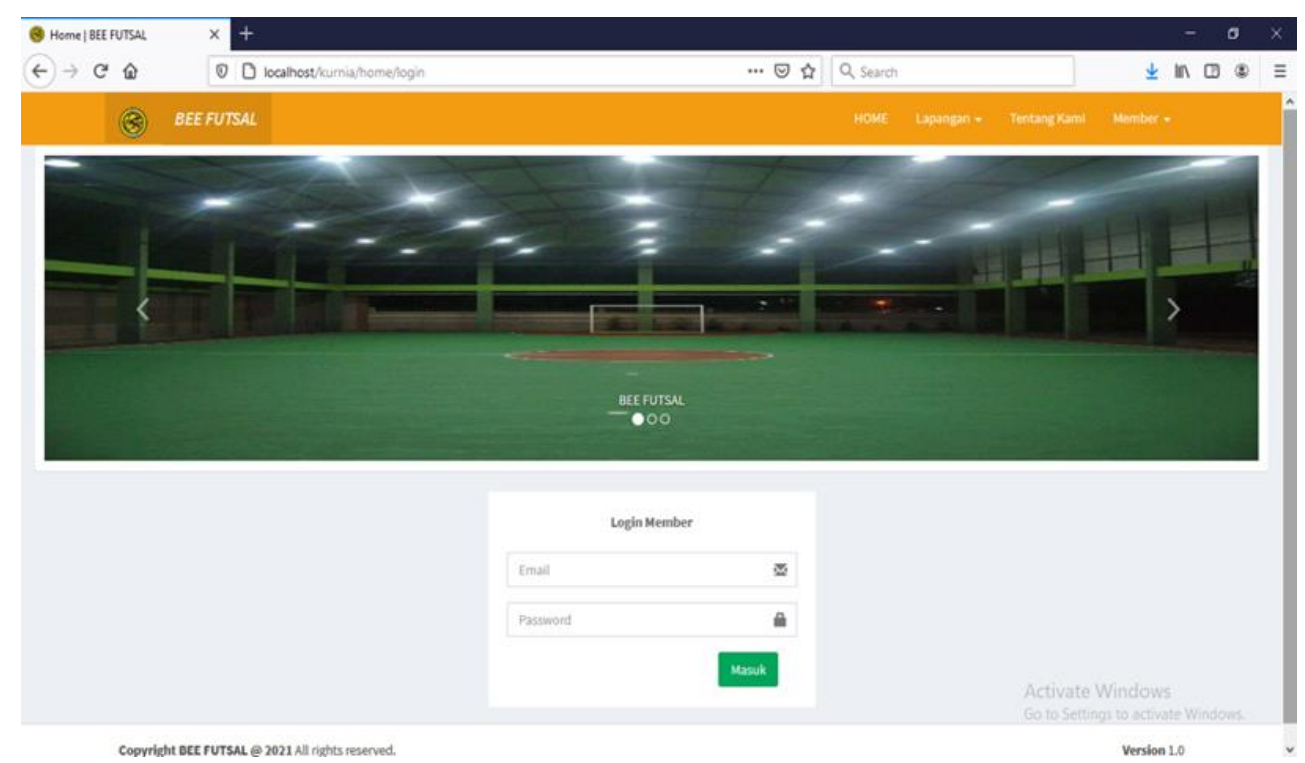

Sumber : Hasil Penelitian (2020)

Gambar 8. Form Login Member

Gambar 8 merupakan tampilan halaman dari form login member customer. Disini pihak customeryang berhasil melakukan registrasi pada halaman sebelumnya. D apat melalkukan login akun dengan cara memasukan email dan password yang telah didaftarkan.

h. Tampilan Form Reservasi Lapangan

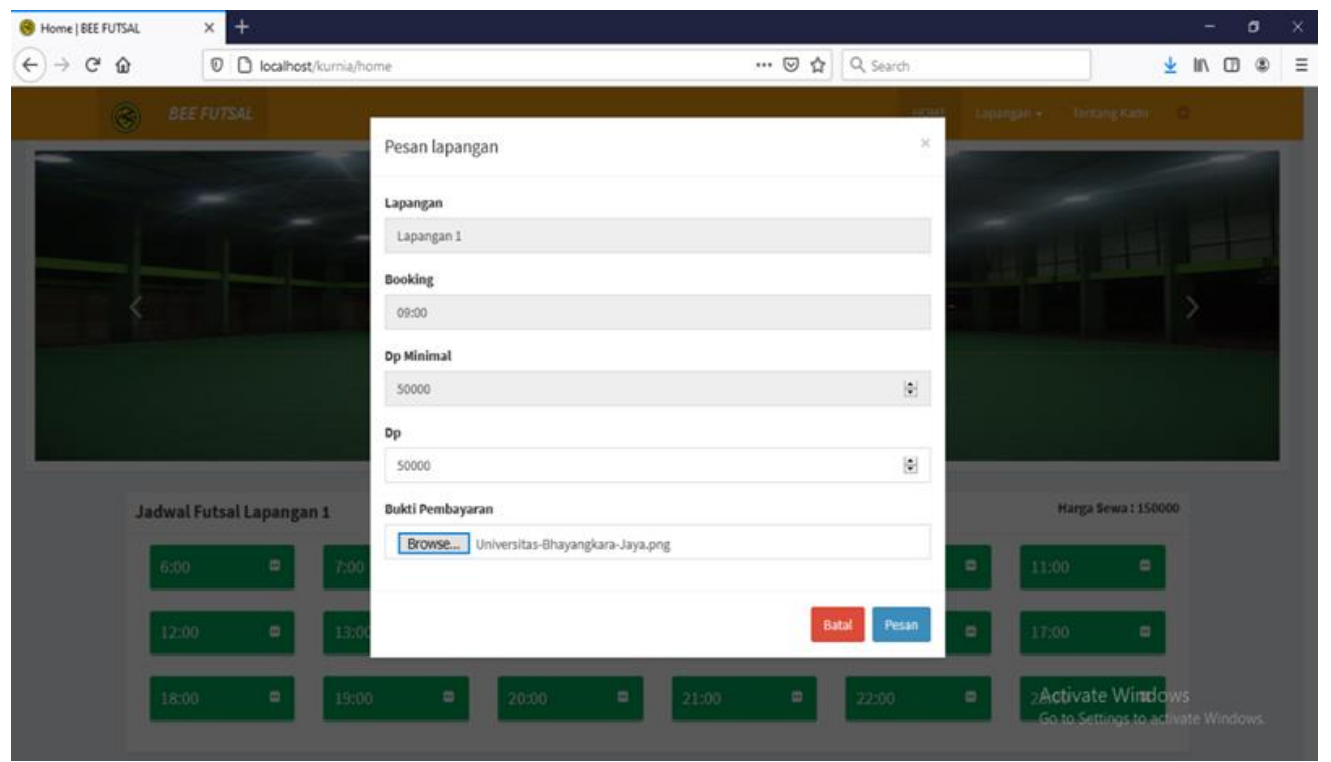

Sumber : Hasil Penelitian (2020)

Gambar 9. Form Reservasi Lapangan

Gambar 9 merupakan tampilan form reservasi lapangan yang hanya bisa diakses oleh pihak customeryang telah berhasil malakukan login. Pada halaman ini pihak customer dapat 
memilih lapangan dan jam lapangan akan dipesan. Setelah itu pihak customer harus membayarkan uang muka dan mengupload bukti pembayarannya di form ini.

\section{Kesimpulan}

Berdasarkan penelitian yang sudah dilakukan ini, dapat diseimpulkan beberapa hal sebagai berikut (a) Sistem informasi reservasi lapangan futsal berbas is Web dan Whatsapp gateway pada Bee Futsal membantu customer melakukan reservasi lapangan dimanapun dan kapanpun, (b) Data reservasi lapangan sudah dikelola dengan menggunakan sistem, sehingga tidak perlu khawatir data akan rusak ataupun hilang, dan (c) Informasi yang dapat diakses customer lebih transparan dan sesuai dengan kebutuhan, informasi meliputi jam kosong, harga sewa, dan spesifikasi lapangan. Adapun saran untuk penelitian selanjutnya adalah perlu dilakukan pengembangan lebih lanjut terhadap Sistem Informasi Reservasi Bee Futsal cengkareng khususnya pada menu reservasi customer. Pengembangan tersebut berupa pilihan jadwal reservasi, sehingga pihak customer bisa memilih hari dan tanggal akan melakukan reservasi jadi tidak hanya bisa melakukan reservasi dihari yang sama.

\section{Daftar Pustaka}

Ameldi, R., \& Ahsyar, T. K. (2018). Sistem Informasi Reservasi Lapangan Futsal Berbasis Android Pada Lapangan Futsal. Jurnal IImiah Rekayasa Dan Manejemn Sistem Informasi, 4(1), 81-90.

Erma Standsyah, R., \& Sari Restu, I. N. (2017). Implementasi Phpmyadmin Pada Rancangan Sistem Pengadministrasian. Jurnal UJMC, 3(2), 38-44. http://ejurnal.unisda.ac.id/index.php/ujmc/article/view/467

Jaya, T. S. (2018). Pengujian Aplikasi dengan Metode Blackbox Testing Boundary Value Analysis (Studi Kasus: Kantor Digital Politeknik Negeri Lampung). Jurnal Informatika Pengembangan IT (JPIT), 3(2), 45-48. https://doi.org/10.30591/jpit.v3i1.647

Kurniawan, D. A. (2020). Aplikasi Peminjaman Ruangan Dan Gedung Pada Universitas Mercu Buana Kampus $D$ Jatisampurna Berbasis Web.

Masrur, M. (n.d.). Open Library - Pemrograman Web Dinamis menggunakan Java Server Pages dengan Database Relasional MYSQL. ANDI Yogyakarta. Retrieved June 25, 2021, from https://openlibrary.telkomuniversity.ac.id/pustaka/121061/pemrograman-web-dinamismenggunakan-java-server-pages-dengan-database-relasional-mysql.html

Pratama, I. . (2014). Sistem Informasi dan Implementasi.

Septavia, I., Gunadhi, E., \& Kurniawati, R. (2016). Sistem Informasi Penyewaan Mobil Berbasis Web di Jasa Karunia Tour And Travel. Jurnal Algoritma, 12(2), 534-540. https://doi.org/10.33364/algoritma/v.12-2.534

Sukamto, R. A. (n.d.). Open Library - Rekayasa Perangkat Lunak : Terstruktur dan berorientasi objek. Informatika Bandung. Retrieved June 25, 2021, from https://openlibrary.telkomuniversity.ac.id/pustaka/30286/rekayasa-perangkat-lunak- 
terstruktur-dan-berorientasi-objek.html

Tohari, H. (2014). Analisis Serta Perancangan Sistem Informasi Melalui Pendekatan UML.

Widharma, I. G. S. (2017). Perancangan Simulasi Sistem Pendaftaran Kursus Berbasis Web Dengan Metode SDLC. Matrix : Jurnal Manajemen Teknologi Dan Informatika, 7(2), 38. https://doi.org/10.31940/matrix.v7i2.527 